\title{
Sorption of chlorhexidine on cellulose: Mechanism of binding and molecular recognition
}

Richard S. Blackburn ${ }^{a}$, Anna Harvey ${ }^{a}$, Lorna L. Kettle ${ }^{b}$,John D. Payne ${ }^{c}$ and Stephen J. Russell ${ }^{a}$

\section{Supporting Information}

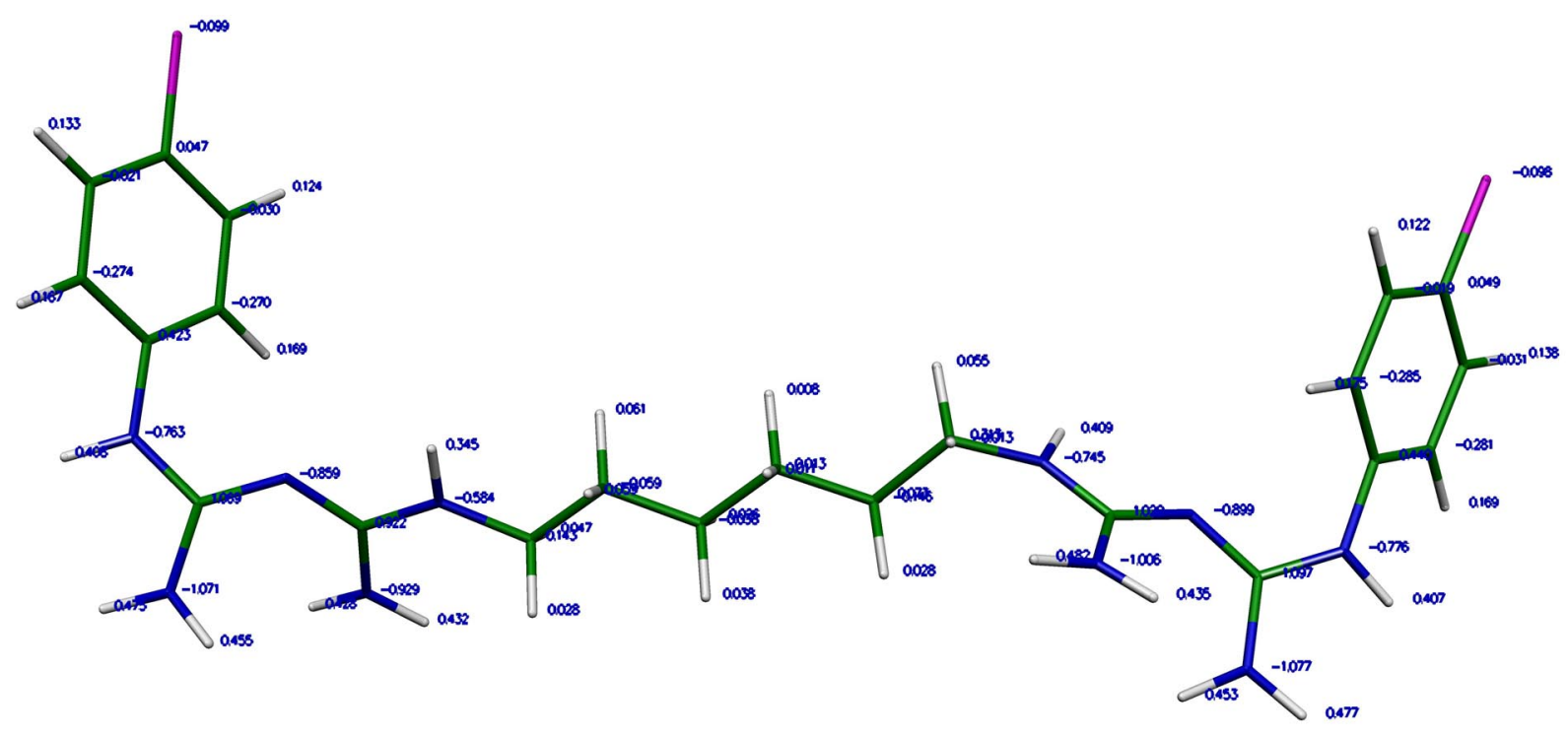

Figure S.1. Chlorhexidine; atoms are labelled with CHELPG charges. 


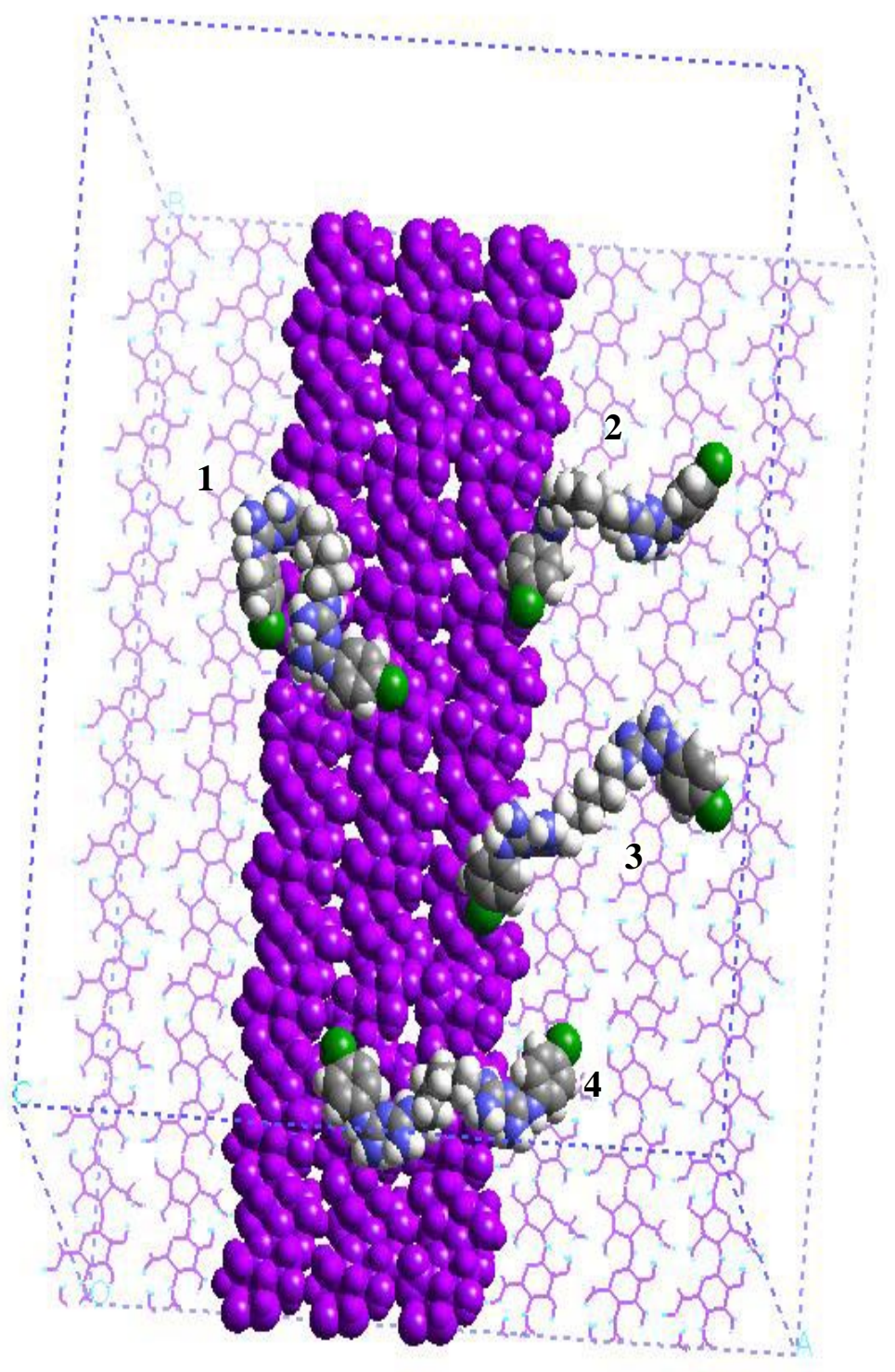

Figure S.2. Four chlorhexidine molecules interacting with a cellulose surface. 
Table S.1. Molecular dynamics simulations of interactions of chlorhexidine with cellulose (All distances in $\AA$ )

\begin{tabular}{|c|c|c|c|}
\hline Molecule & Simulation 1 & Simulation 2 & Simulation 3 \\
\hline 1 & Possible ring sitting on surface & $\begin{array}{l}\text { Ring sitting on surface with } \\
\text { possible interactions: } \\
\text { Sugar-H...Ph }=2.47-2.50 \\
\text { Sugar-H...HN }=2.31 \\
\mathrm{H}-\mathrm{O} \ldots . . \mathrm{H}-\mathrm{Ph}=2.90\end{array}$ & $\begin{array}{l}\text { Electrostatic interactions with } \\
\mathrm{COO}^{-} \text {group } \\
\text { Hydrogen bonding between BG } \\
\text { and } \mathrm{OH} \text { groups }\end{array}$ \\
\hline 2 & $\begin{array}{l}\text { Hydrogen bonding between } \mathrm{BG} \\
\text { and } \mathrm{OH} \text { groups }\end{array}$ & $\mathrm{COO}^{-} \ldots \mathrm{H}-\mathrm{Ph}=2.60$ & $\begin{array}{l}\text { Electrostatic interactions with } \\
\mathrm{COO}^{-} \text {group }\end{array}$ \\
\hline 3 & $\begin{array}{l}\text { Electrostatic interactions with } \\
\mathrm{COO}^{-} \text {group }\end{array}$ & $\begin{array}{l}\text { Involving BG: } \\
\mathrm{COO}^{-} \ldots \mathrm{HN}=2.60 \\
\mathrm{H}-\mathrm{O} \ldots \mathrm{HN}=2.70 \\
\mathrm{H}-\mathrm{O} \ldots \mathrm{H}_{2} \mathrm{~N}=2.20-2.42 \\
\text { Involving the } \\
\text { chlorophenyl: } \\
\mathrm{H}-\mathrm{O} \ldots \mathrm{H}-\mathrm{Ph}=2.90 \\
\text { sugar-H...Ph }=2.50-2.70\end{array}$ & $\begin{array}{l}\text { Electrostatic interactions with } \\
\mathrm{COO}^{-} \text {group }\end{array}$ \\
\hline 4 & Possible ring sitting on surface & $\mathrm{R}_{2} \mathrm{O} \ldots \mathrm{H}_{2} \mathrm{~N}=2.08-2.30$ & $\begin{array}{l}\text { Electrostatic interactions with } \\
\mathrm{COO}^{-} \text {group }\end{array}$ \\
\hline
\end{tabular}

